\title{
MODELAGEM MATEMÁTICA PARA SELEÇÃO DE ÁREAS PRIORITÁRIAS À CONSERVAÇÃO OU RESTAURAÇÃO NO CERRADO GOIANO
}

\author{
mathematical model for selection of priority areas for \\ conservation or restoration in the Cerrado Goiano \\ Maria Socorro Duarte da Silva Couto* \\ Ole Peter Smith** \\ Renato Araújo Teixeira***
}

\begin{abstract}
Resumo
O uso de modelagem matemática constitui-se em importante subsídio técnico aos problemas de conservação ao possibilitar a identificação de alternativas mais eficazes. Neste artigo, definiu-se e analisou-se um modelo matemático de programação não linear de seleção de áreas prioritárias para conservação/restauração, que considera a qualidade e viabilidade ecológica das áreas de vegetação remanescente do Cerrado goiano, principalmente, a influência das áreas de cana de açúcar na região que envolve os municípios de Goiânia e Inhumas, bem como as bacias do rio Meia Ponte e a do rio João Leite. O método adotado partiu do uso de dados e critérios ambientais por meio da paisagem. Os resultados demonstram que as áreas prioritárias para conservação da biodiversidade estão concentradas na bacia do rio João Leite. Entretanto, as áreas que mais necessitam de restauração encontram-se na bacia do rio Meia Ponte, na qual se constatou uma elevada demanda por biocombustíveis e perda de habitat.
\end{abstract}

Palavras-chave: Áreas prioritárias, Conservação no Bioma Cerrado, Otimização, Programação Não Linear.

\begin{abstract}
The use of mathematical modeling constitutes as an important technical benefit to the conservation problems, enabling identification of more effective alternatives. In this paper we define and analyze a mathematical modeling of nonlinear programming selection of priority areas for conservation/restoration, that consider the quality and ecological viability of remnant vegetation areas of the Cerrado goiano, especially the influence of the sugar cane fields in the region surrounding the cities of Goiannia and Inhumas and, the watersheds of Meia Ponte river and João Leite river. The method used was based on the use of data and environmental standards through the landscape. The results show that the priority areas for biodiversity conservation are concentrated in the João Leite river. However, the areas most in need for restoration are located at the Meia Ponte river watersheds, in which we found a high demand for biofuels and habitat loss.
\end{abstract}

Key words: Priority Areas, Conservation in Cerrado, Optimization, Non Linear Programming.

\section{Resumen}

El uso de modelos matemáticos que constituye un beneficio importante técnica a los problemas de conservación, para permitir la identificación de alternativas más eficaces. En este artículo nosotros definimos y analizamos un modelo matemático de programación non lineal de selección de áreas prioritarias para la conservación/restauración, que leve en cuenta la calidad y la viabilidad ecológica de las áreas remanentes de vegetación del Cerrado goiano, en especial la influencia de los campos de caña de azúcar en región que abarca las ciudades de Goiânia y Inhumas, así como las bacías del río Meia Ponte y del río João Leite. El método utilizado se basa en la utilización de los datos y las normas ambientales a través del paisaje. Los resultados demuestran que las áreas prioritarias para la conservación de la biodiversidad se concentran en la bacía del río João Leite. Sin embargo, las zonas más necesitadas de la restauración en la bacía del río Meia Ponte, donde encontramos una gran demanda de biocombustibles y la pérdida de hábitat.

Palabras clave: Áreas prioritarias, Conservación en el Bioma Cerrado, Optimización, Programación non Lineal.

(*) Prof $f^{a}$. Drª do Instituto Federal de Educação, Ciência e Tecnologia de Goiás - Av. Universitária s/n Vale das Goiabeiras, CEP: 75400-000 Inhumas (GO), Brasil, Tel: (+5562) 35149540 - socorrodc@inhumas.ifg.edu.br

(**) Prof. Dr. do Instituto Federal de Educação, Ciência e Tecnologia de Goiás - Av. Universitária s/n Vale das Goiabeiras, CEP: 75400-000 Inhumas (GO), Brasil, Tel: (+ 55 62) 35149540 - ole@mat.ufg.br

(***) Prof. Msc. do Instituto Federal de Educação, Ciência e Tecnologia de Goiás - Av. Universitária s/n Vale das Goiabeiras, CEP: 75400-000 Inhumas (GO), Brasil, Tel: (+55 62) 35149540 - renato@inhumas.ifg.edu.br 


\section{INTRODUÇÃO}

O Cerrado, o segundo maior bioma da América do Sul, ocupa uma área de 204 milhões de hectares, abrange 12 estados (IBGE, 2000) e é reconhecido como sendo um dos 34 hotspots de biodiversidade no mundo, isto é, uma área de alto endemismo de biodiversidade e elevado estágio de degradação (MYERS et al., 2000; JHA et al.,2005), causada pela intensa ocupação agropastoril que o transformou na principal fronteira de expansão agrícola brasileira (MIZIARA; FERREIRA, 2008). Sabe-se de forma bastante precisa que $26,5 \%$ e $10,5 \%$ da cobertura vegetal nativa já foram convertidas em pastagens cultivadas e áreas agrícolas, respectivamente (SANO et al., 2008).

Em relação ao cerrado goiano, a ocupação antrópica tem sido igualmente intensa até porque a expectativa é de que os desmatamentos nesse cerrado se acentuem, com taxas de desmatamento que variam de $0,21 \%$ a $0,86 \%$ ao ano (SILVA et al., 2008), um dos elementos desse processo de destruição ocorre em função da crescente demanda por biocombustíveis (RIBEIRO, 2008), como também pela proximidade dos grandes centros consumidores. Por isso, torna-se cada vez mais necessário a adoção de critérios objetivos, por exemplo, o uso de modelagem matemática, com vistas à priorização coerente de áreas e/ou espécies a serem preservadas (CABEZA, 2003; MARGULES; PRESSEY, 2000; MARGULES et al., 2002), levando em conta fatores como a limitação de recursos naturais e econômicos (ARPONEN et al., 2005; MARGULES; PRESSEY, 2000) para assegurar, a longo prazo, a conservação da biodiversidade.

Neste contexto, a região que envolve a grande Goiânia e o município de Inhumas precisa urgentemente de ações que otimizem a conservação de sua biodiversidade e de seus serviços ambientais. Desse modo, é necessário a proteção e a recuperação dos seus principais mananciais de água, como os rios Meia Ponte e João Leite, que são responsáveis pelo abastecimento de água da cidade de Goiânia e entorno. Essas ações devem ter como unidade de aplicação a bacia hidrográfica. A escolha dessa unidade de aplicação se dá tanto pelo aparato legal (Lei 9433, 1997), quanto pelo fato da bacia hidrográfica agregar sistemicamente um conjunto ambiental de elementos físicos, bióticos e socioeconômicos inter-relacionados, bem como ser uma unidade territorial hierarquizável pelo número de nascentes e cursos d'água (SANTOS, 2004).

Ressalta-se que, a própria legislação florestal brasileira estabelece uma área mínima de cobertura vegetal nativa de $20 \%$ no estado de Goiás de reserva legal (o percentual é variável dentre os estados e regiões fitoecológicas), sem incluir as áreas de preservação permanente (APPs), associadas, dentre outras, às margens de cursos d'água, ao entorno de nascentes, veredas, lagos, lagoas ou reservatórios, como também, a topos de morros, montes, montanhas e serras, áreas declivosas e linhas de ruptura de relevo, o que reforça a necessidade de restauração de pelo menos algumas áreas degradadas e compreensão dos padrões espaciais de ocupação dessa região.

Tendo em vista a crescente demanda por fontes alternativas de energia renováveis que vem gerando uma expansão acelerada e pouco planejada, principalmente em áreas do bioma Cerrado, que pode resultar em significativas consequências negativas tanto para a biodiversidade, quanto para os serviços ambientais em geral, sobretudo, os recursos hídricos.

Nesse contexto, apresenta-se uma nova proposta para identificação de áreas prioritárias para conservação da biodiversidade da região que envolve os municípios de Goiânia e Inhumas e as bacias do rio Meia Ponte e a do rio João Leite, a partir de ajustes no modelo matemático de programação não linear proposto por Couto et al. (2010).

Em seguida, expõe-se o estudo da variação de parâmetros dos objetos de conservação e a análise do avanço das áreas de cana de açúcar, com vistas a gerar novos cenários voltados à gestão territorial e a consolidação da conservação da biodiversidade, dos serviços ambientais e de paisagens dessa região.

Por fim, indica-se quais as áreas prioritárias para restauração, com o intuito de maximizar o potencial de conservação dos ambientes ripários, isto é, dos cursos d'água, nascentes, veredas, lagos, lagoas ou reservatórios, principalmente, ao longo dos rios Meia Ponte e João Leite. Nesse 
sentido, pretende-se contribuir, de certa forma, na manutenção e revitalização desses rios.

\section{MATERIAL E MÉTODOS}

Este trabalho tem como área de estudo a região que envolve os municípios de Goiânia e Inhumas e as bacias do rio Meia Ponte e do rio João Leite, que é composta por dezesseis bacias hidrográficas de nível menor e maiores de 10 mil hectares, caracterizadas pelo elevado índice de degradação ambiental, com aproximadamente 90\% de sua área antropizada (Figura 1).

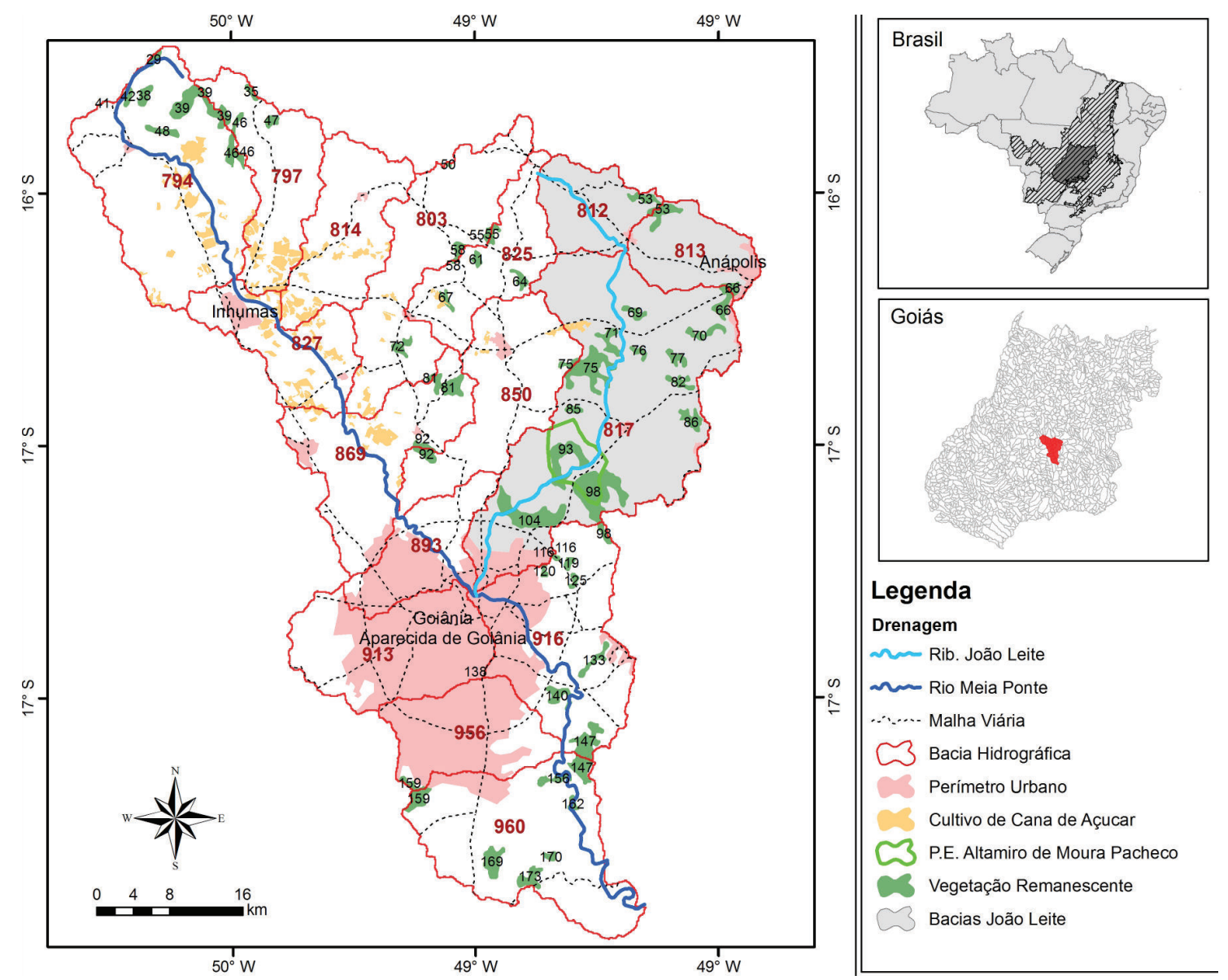

Figura 1 - Localização e distribuição de vegetação remanescente e de áreas de cana de açúcar.

O conjunto de dados primários (cartográficos, temáticos, censitários, orbitais e econômicos), os procedimentos e os dados derivados (produtos), referentes a este trabalho, são detalhados através do diagrama da Figura 2.

O modelo de seleção de áreas prioritárias para conservação proposto por Couto et al. (2010) sofreu alguns ajustes para a área de estudo em questão. Trata-se de um modelo de programação não linear com uso de uma unidade de análise natural (bacias hidrográficas), coerente com os aspectos fisiográficos da paisagem. De fato, o uso de bacia hidrográfica, neste trabalho, é importante tanto pelo seu aparato legal (Lei 9433, 1997), quanto pelo fato dela agregar sistemicamente um conjunto ambiental de elementos físicos, bióticos e socioeconômicos inter-relacionados, bem como por ser uma unidade territorial hierarquizável pelo número de nascentes e cursos d'água (SANTOS, 2004). 


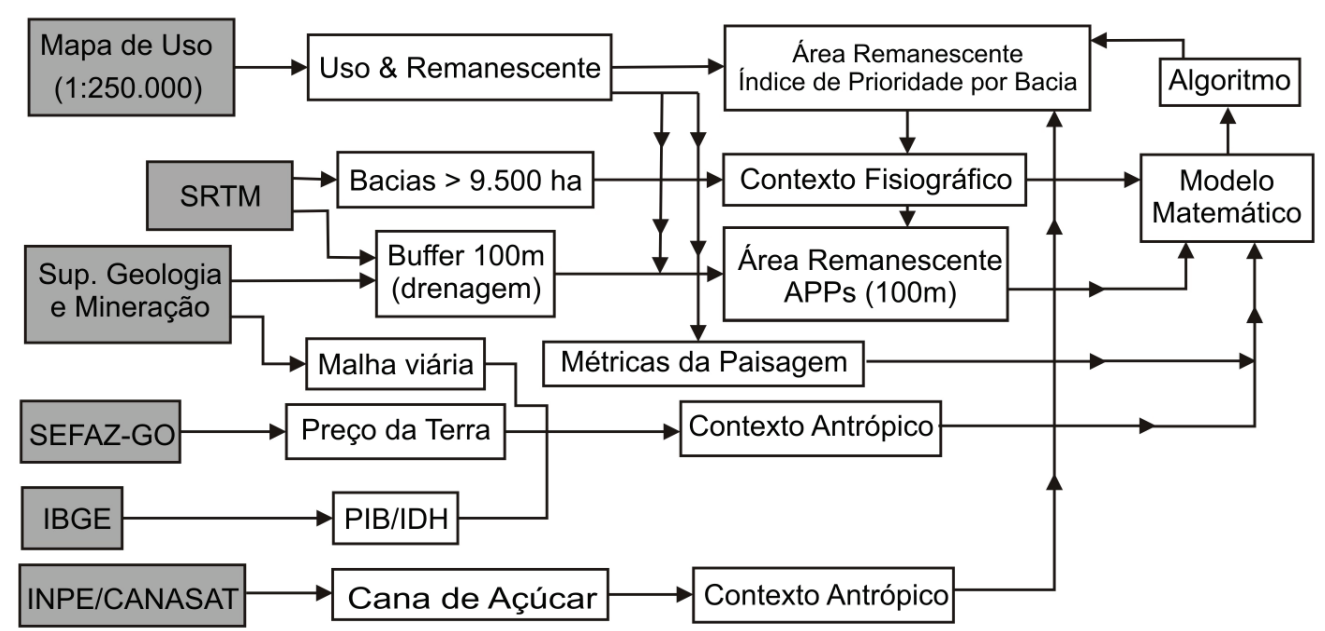

Figura 2 - Conjunto de dados primários e procedimentos metodológicos aplicados à área de estudo para identificação de áreas prioritárias.

A função desse modelo consiste em minimizar o número de áreas prioritárias para conservação em nível de bacias, diminuindo a soma das distâncias entre as áreas selecionadas, ao mesmo tempo em que maximiza a qualidade das mesmas para conservação da biodiversidade.

Tendo em vista a escala do mapa de cobertura e uso da terra usado neste trabalho (1:250.000), foram considerados nas análises do modelo matemático todos os fragmentos remanescentes detectados, que correspondem a menos de $10 \%$ da área de estudo.

Procurou-se organizar o conjunto de dados primários de forma que as variáveis, através do algoritmo computacional heurístico usado e implementado na Linguagem C, ficaram separadas em arquivos de acordo com suas características, os quais foram automatizados para produzir saídas em formato .csv (comma separated values). Além de agilizar o processo de encontrar a solução, esse formato é compatível com o programa ArcGis 9.0, utilizado na criação dos mapas das soluções do problema.

Esse algoritmo se baseia na Teoria de Grafos para traduzir dados geográficos como posição relativa de pontos e ordenamento espacial da informação (AGNARSSON e GREENLAW, 2007; BANG-JENSEN; GUTIN, 2001), determinando soluções para seleção de áreas para conservação, que otimize a conectividade entre o conjunto de bacias hidrográficas selecionadas. Além disso, cada bacia selecionada na solução possui um índice de importância, que varia de 0 a 1 , o qual indica a relevância de inclusão da bacia com propósito de preservação, procurando determinar soluções com áreas mais aglomeradas, favorecendo a viabilidade ecológica, o custo de conservação e a redução dos atritos entre a conservação da biodiversidade e o desenvolvimento socioeconômico regional (CABEZA; MOILANEN, 2001).

\section{RESULTADOS E DISCUSSÕES}

O modelo de seleção de áreas prioritárias para conservação e/ou restauração que é proposto para essa área de estudo é uma adaptação do modelo de Couto et al. (2010):

$$
\begin{aligned}
& \operatorname{Min} \sum\left[-\left(\frac{c_{1}}{P_{i}}+\frac{c_{2}}{Q_{i}}+\frac{c_{3}}{I_{i}}\right) \cdot(1-\alpha(i)) a_{i}-c_{4}(1-\alpha(i)) b_{i}+c_{5} \cdot\left(\frac{p_{i}}{a_{i}}\right)-c_{6} \cdot \beta(i)+\right. \\
& \left.c_{7} \cdot r_{i}-c_{8} \cdot d_{i}+\frac{c_{9} \alpha_{i}^{T} D \alpha_{i}}{\left(g^{2}(i)-g(i)\right)}\right] \\
& \text { s.a. } \sum \alpha(i) \cdot a_{i} \geq k a_{i}
\end{aligned}
$$


onde,

$c_{i} i=1,2, \ldots, 10$ são os parâmetros.

As variáveis do modelo são:

$a_{i}=$ área do fragmento de vegetação remanescente $i$ dentro da bacia;

$b_{i}=$ área de buffer do fragmento de vegetação remanescente $i$ dentro da bacia;

$P_{i}, Q_{i}$ e $I_{i}=$ correspondem ao Preço da Terra, PIB e IDH, respectivamente, do município que contém o fragmento de vegetação remanescente $i$;

$e_{i j}=$ vetor de presença ou ausência de espécie $j$ dentro do fragmento remanescente $i$;

$p_{i} / a_{i}=$ razão entre o perímetro e a área do fragmento remanescente $i$;

$r_{\mathrm{i}}=$ nível de influência sofrida $(0,1 / 2$ ou 1$)$ do fragmento remanescente $i$ com a rodovia;

$d_{i}=$ distância de saída da sub-região hídrica (ou simplesmente, distância hídrica), isto é, o número de fragmentos de vegetação remanescentes que estão rio abaixo do fragmento $i$ até o ponto final da linha de drenagem, essa distância ajuda a identificar o fragmento de vegetação remanescente que faz parte de uma nascente.

$D=$ matriz de distância entre os centroides dos fragmentos de vegetação remanescente.

$k=$ porcentagem de área de vegetação remanescente a ser priorizada.

$\alpha(i)=$ variável de qualidade/importância de inclusão do fragmento remanescente $i$ em proposta de conservação. Essa variável tem valor inicial de zero e varia ao longo do algoritmo. A determinação de seu valor é a finalidade do algoritmo;

$\beta(i)=$ variável que reflete a existência de fragmentos remanescentes adjacentes ao fragmento $i$ na proposta de conservação.

Inicialmente, aplica-se para a área de estudo valores de parâmetros que dão peso aproximadamente igualitário a cada fator da função objetivo do modelo matemático (1), obtendo-se uma solução padrão, para depois fazer o estudo da variação dos parâmetros em torno dessa solução tal que, quanto maior o peso atribuído ao parâmetro, maior é a probabilidade, por um lado, de inclusão das áreas de maior viabilidade ecológica, por outro, de exclusão das áreas de maior ação antrópica.

Os valores dos parâmetros da solução padrão são: $c_{1}=2.000, c_{2}=20.000, c_{3}=0,2, c_{4}=20$, $c_{5}=100.000, c_{6}=1.000, c_{7}=12.000, c_{8}=1.000, c_{9}=0,25 \mathrm{e} \mathrm{k}=0,7$ (COUTO et al, 2010).

A variação dos parâmetros ci, geralmente determinam soluções distintas e a discussão sobre a natureza. A sensibilidade das mesmas depende dos valores atribuídos aos ci, de acordo com as condições e os interesses envolvidos na área de estudo.

Neste trabalho, realizou-se o estudo da variação individual de cada parâmetro $c_{i}$, tomando vários valores equidistantes do seu intervalo, de forma que ao variá-lo os outros parâmetros são fixos em relação à solução padrão. Assim, para cada valor atribuído ao ci foi gerada uma solução. Para facilitar as análises e medir as possíveis alterações entre as soluções geradas, definiu-se, nesse caso, a distância X como sendo a raiz quadrada da soma do quadrado da diferença entre o vetor solução do parâmetro que foi variado e o vetor solução padrão.

Nessa área de estudo, observou-se que as soluções obtidas com a variação dos parâmetros $c_{1}$, $c_{2}$ e $c_{3}$ foram idênticas, ou seja, a distância $\mathrm{X}$ foi nula entre todas as soluções obtidas. Isto ocorreu por se tratar de uma área bastante degradada, em que a variação do preço da terra, PIB e IDH é baixa, e, nesse caso, essas variáveis não influenciaram na solução. 
Na variação do parâmetro $c_{4}$ no intervalo $[0,80]$, observou-se que as soluções são constantes para valores que estão até pouco mais da metade desse intervalo. Essas soluções sofrem poucas alterações $(\mathrm{X}<0,06)$ para valores maiores que estão mais próximos a extremidade superior do intervalo. Isso significa que as áreas de vegetação remanescente ao longo da linha de drenagem (buffers), que fazem parte dos ambientes ripários, pouco influenciaram na solução do problema, o que se deve ao fato de que áreas de preservação permanente, como as de ambientes ripários, estão bastante restritas na região que envolve os municípios de Goiânia e Inhumas e as bacias do rio Meia Ponte e do rio João Leite, diminuindo a possibilidade de inclusão de determinadas bacias hidrográficas na solução.

Quanto à variação do parâmetro $c_{5}$ no intervalo [0,400.000], que está relacionado ao formato das áreas de vegetação remanescente, no qual se prioriza as de maior área e de pouca borda, notou-se que as soluções são mais distintas para os valores mais próximos do extremo superior desse intervalo, nesse caso, o maior valor encontrado para $\mathrm{X}$ foi 1,67. Por exemplo, nota-se claramente essa diferença na região do rio João Leite, tendo em vista que nela se encontra as maiores áreas de vegetação remanescente (Figuras 3 e 4).

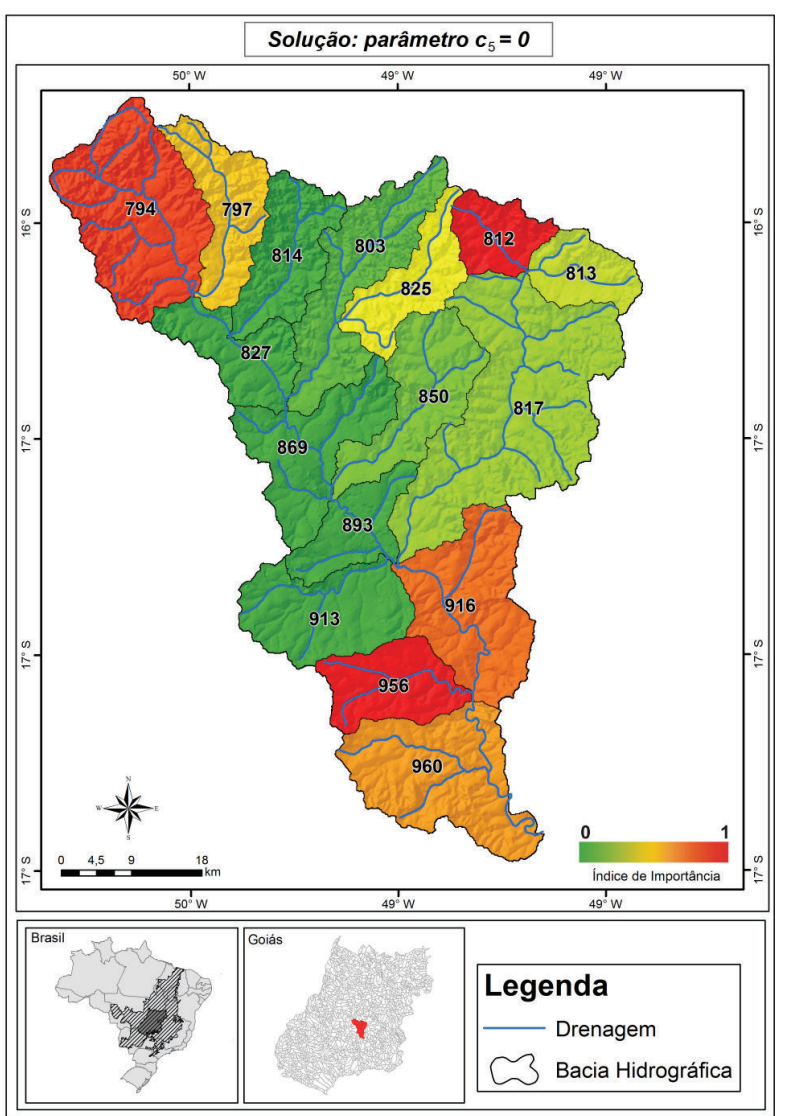

Figura 3 - Solução: parâmetro c5=0

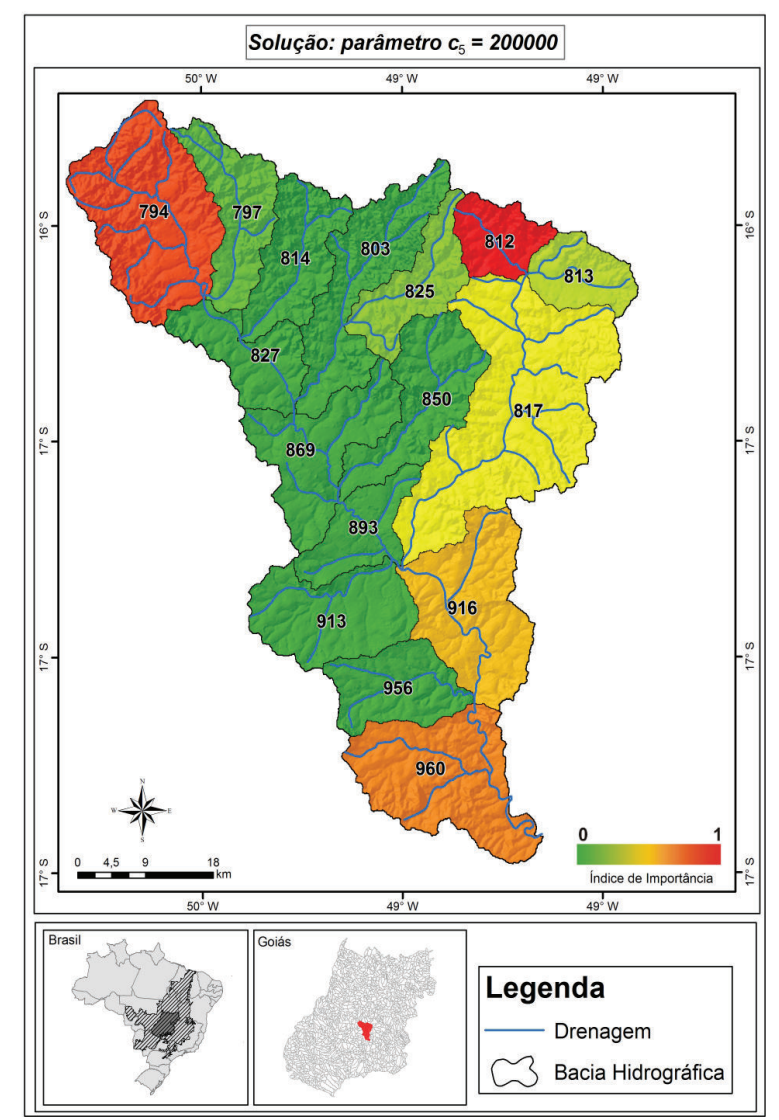

Figura 4. -Solução: parâmetro c5=200.000

Nas soluções em que se variou somente o peso do parâmetro referente à vizinhança e a conectividade $\left(c_{6}\right)$, observou-se que a maior distância $(\mathrm{X}=1,33)$ ocorreu para os valores maiores ou iguais $c_{6}=3.000$, o que significa, em termos de nível de importância das bacias, que houve um maior adensamento das áreas de vegetação remanescente na solução. Esse fato foi visivelmente observado na bacia do rio João Leite (Figuras 5 e 6).

É interessante observar (Figura 6) que na bacia do rio João Leite, o adensamento de áreas ocorre na região onde se localiza o Parque Estadual Altamiro de Moura Pacheco, situado na bacia 817. De fato, por se tratar de uma unidade de conservação integral, esse induz à conservação de suas áreas circunvizinhas. 
Constatou-se que foi o parâmetro referente ao nível de influência da malha viária $\left(c_{7}\right)$, que provocou a maior diferença entre as soluções $(X=2,25)$. De fato, os fragmentos de vegetação remanescente da bacia do rio João Leite sofrem muita influência da malha viária na solução, a principal delas é em razão de a BR 153 interceptar o Parque Estadual Altamiro de Moura Pacheco, é uma das maiores áreas de vegetação remanescente da área em estudo (Figuras 7 e 8). Com isso, favoreceu-se a seleção de outras áreas na solução que não tinham tanta interferência da malha viária, por exemplo, a maior priorização das bacias 794 e 812 (Figura 8), que contêm a nascente do rio Meia Ponte e a nascente do rio João Leite.

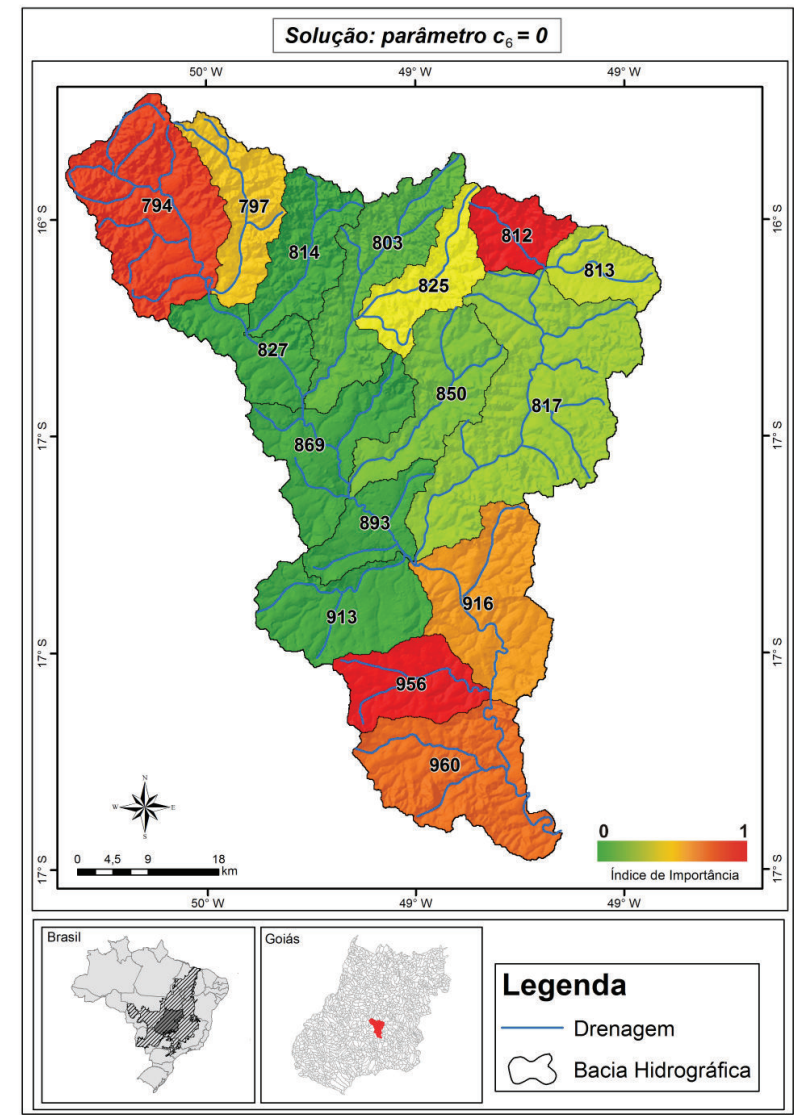

Figura 5 - Solução: parâmetro c6=0.

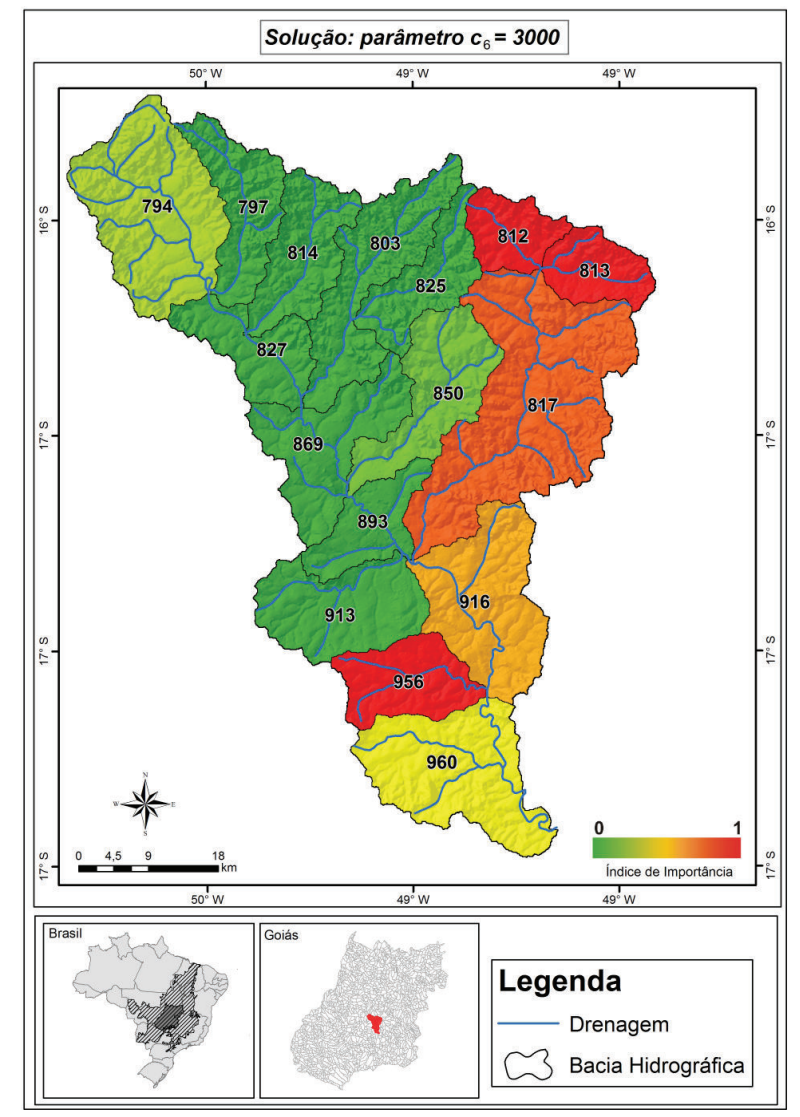

Figura 6 - Solução: parâmetro c6=3.000.

Na variação do parâmetro referente à distância hídrica $\left(c_{8}\right)$, notou-se que a diferença entre as soluções foi pouco significativa $(X<0,09)$. Isso é o reflexo da existência de poucos fragmentos de vegetação remanescentes que fazem parte de alguma nascente e/ou estejam ao longo de alguma linha de drenagem.

O último parâmetro a ser analisado refere-se a distância entre os fragmentos de vegetação remanescente $\left(c_{9}\right)$, cuja variação gerou soluções relativamente distintas $(\mathrm{X}<1,55)$, no qual o aumento de seus valores procurou incluir na solução as áreas de vegetação remanescente que fossem mais próximas entre si, como as da bacia do rio João Leite.

Tendo em vista que o aumento do valor dos parâmetros $c_{6}$ e $c_{9}$ levam a obter soluções que selecionam a bacia do rio João Leite como áreas prioritárias para conservação, por possuir uma concentração maior de fragmentos de vegetação remanescente, verificou-se que o cenário gerado para valores altos de $c_{9}$ é bastante semelhante ao do parâmetro $c_{6}$ (Figura 6).

Entre as várias soluções de seleção de áreas para conservação encontradas com a variação dos parâmetros, definiu-se como sendo uma solução ótima para conservação dessa área de estudo a solução que possui elevado índice de ambientes ripários e de vegetação remanescente $\left(c_{4}=60\right)$, 
que valoriza a vizinhança, a conectividade entre as áreas $\left(c_{6}=3.000\right)$ e os fragmentos de vegetação remanescente que faz parte de nascentes $\left(c_{8}=2.500\right)$ e minimiza da distância entre as áreas $\left(c_{9}=2\right)$, ao mesmo tempo em que também minimiza os efeitos das variáveis antrópicas sobre a conservação dessas áreas (Figura 9).

A partir dessa solução ótima (Figura 9) verificou-se que as bacias com maior nível de importância para conservação (em tons de vermelho) estão concentradas na bacia do rio João Leite. De fato, como já foi observado (Figura 1) essa é a região que contém a maior concentração de vegetação remanescente, fator que foi decisivo nesse problema, apesar de corresponder menos de 30\% de cobertura vegetal, valor estimado por Bonnet et al. (2006) para atender aos requerimentos do Código Florestal. Observou-se que em algumas bacias dessa região a situação é mais crítica com uma quantidade bastante reduzida de vegetação, como a bacia 812 , que possui uma das principais nascentes do rio João Leite.

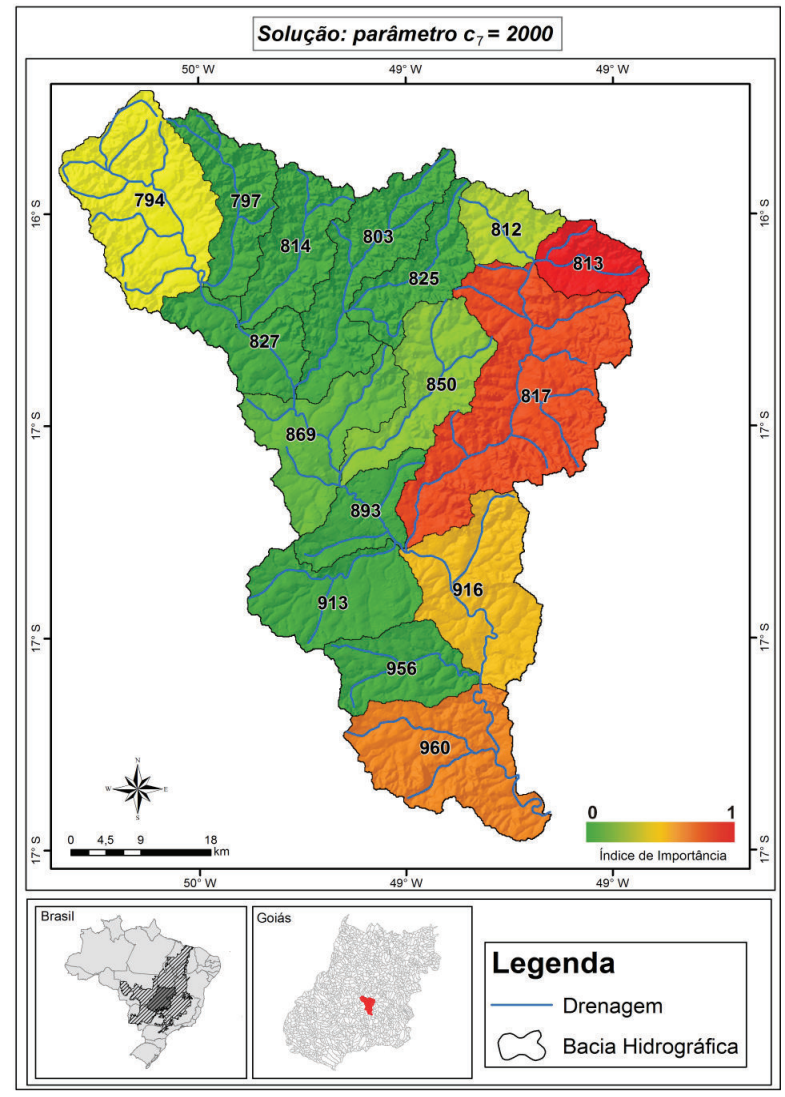

Figura 7 - Solução: parâmetro c7=2.000

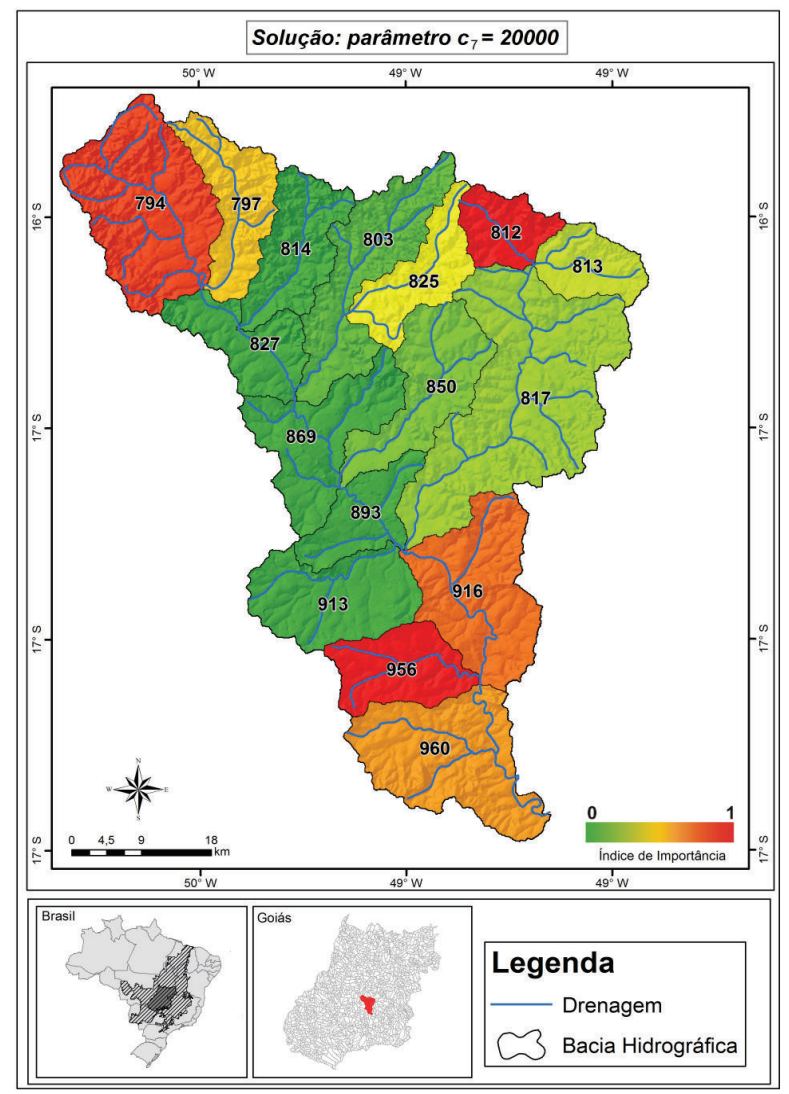

Figura 8 - Solução: parâmetro c7=20.000

É importante ressaltar que o modelo matemático proposto pode contribuir tanto para valorização das áreas de vegetação remanescente para proposta de conservação, quanto para otimizar a restauração da biodiversidade de áreas degradadas (COUTO, 2010). Os dois enfoques de aplicação do modelo matemático não são mutuamente excludentes. Pelo contrário, podem ser complementares, isso significa que as bacias com os menores níveis de importância para conservação são justamente aquelas que devem ser priorizadas para a restauração da biodiversidade e dos serviços ambientais, principalmente dos recursos hídricos.

Com esse intuito, observou-se na Figura 9 que as bacias com os menores níveis de importância para conservação (em tons de verde), estão localizadas na bacia do rio Meia Ponte. Trata-se, nesse caso, de uma região onde a ação antrópica é caracterizada, entre outras, pela grande concentração de áreas de cultivo de cana de açúcar que estão localizadas (Figura 10): ao longo do rio Meia Ponte, onde a baixa declividade $\left(<7^{\circ}\right)$ propicia a mecanização; próximas à malha viária, que facilita 
o escoamento da produção; próximas à usina, o que reduz o custo de transporte e; relativamente próximas à cidade de Goiânia, grande centro consumidor de etanol.

O presente artigo propõe como um ponto de partida para a restauração da bacia do rio Meia Ponte os ambientes ripários (nascentes e ao longo das linhas de drenagem), que estão altamente degradados. O motivo dessa escolha se dá tanto pelo aparato legal (Lei 9433, 1997), quanto pelo fato de os ambientes ripários serem importantes para a natureza, pois são responsáveis pela retenção de água no sistema de armazenagem subterrânea, pelo controle de processos erosivos e de assoreamento de corpos hídricos, pelo nível de quantidade e de qualidade da água, pelo abastecimento hídrico de populações animais, vegetais e humanas com seus sistemas de produção e por serem viáveis a alcançarem o status de corredores ecológicos, os quais favorecem a fluidez dos fluxos genéticos entre os seres vivos dos habitats fragmentados, funciona como fonte de alimentos para a fauna aquática e avifauna, propiciando, dessa forma, a conservação da biodiversidade.

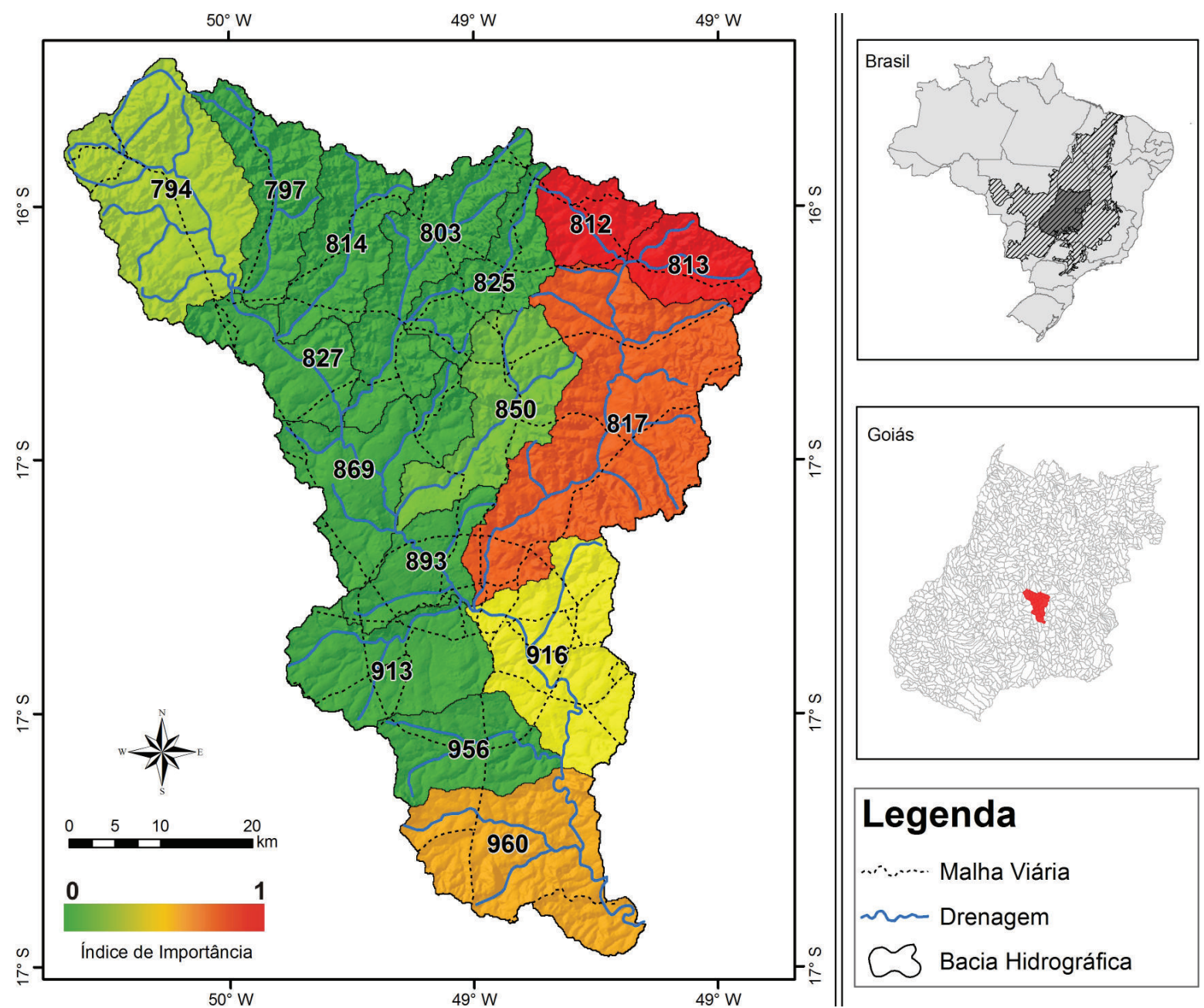

Figura 9 - Solução Ótima - nível de importância das bacias para priorização de áreas para conservação.

Infelizmente, o processo de restauração, nessa área de estudo, está se tornando cada vez mais difícil devido às características físicas (topografia, solo e clima), econômicas e de infraestrutura, que propiciam a intensificação ou expansão do setor sucroalcooleiro na região (MIZIARA et al., 2008). 


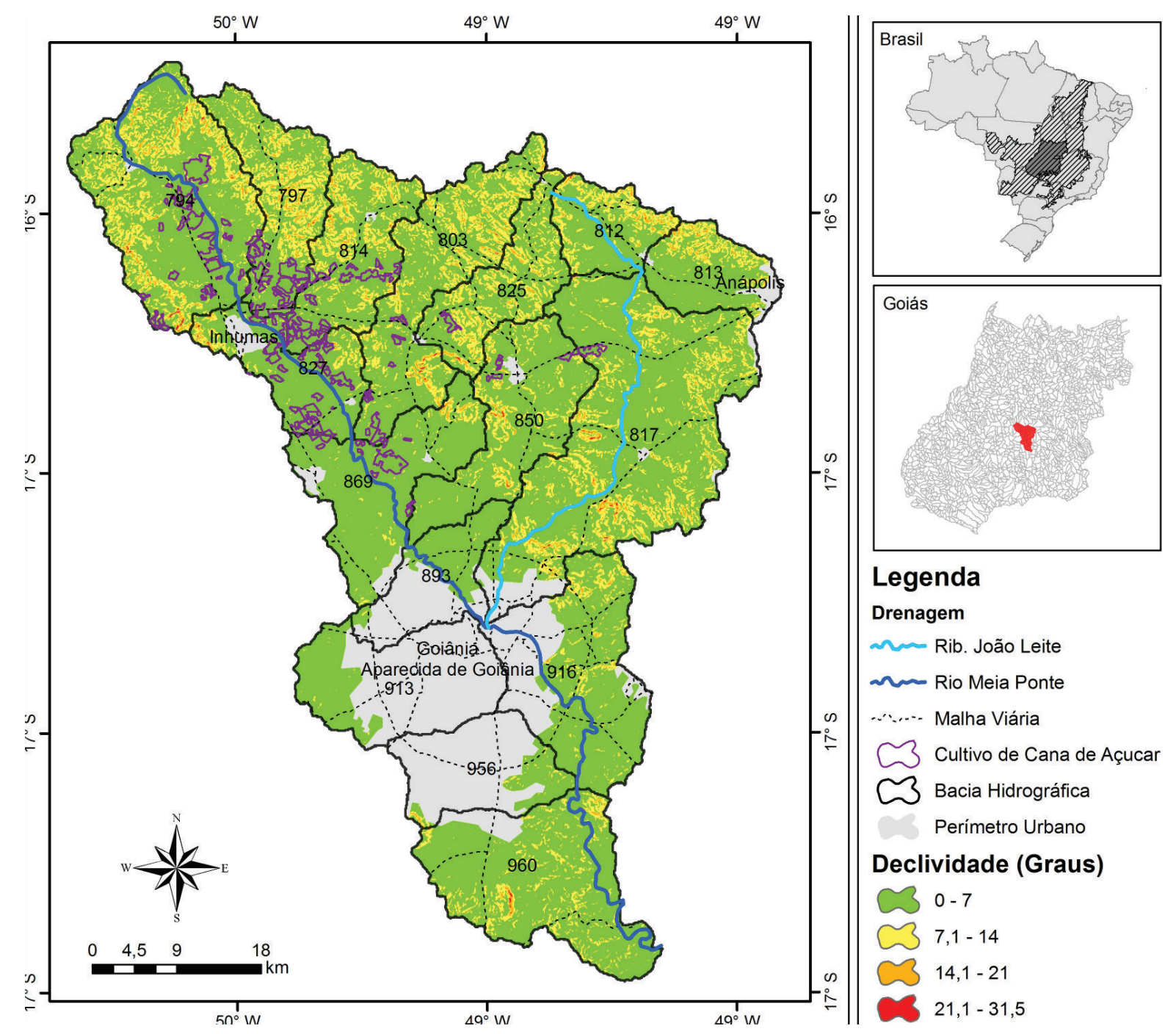

Figura 10 - Mapa de declividade e área ocupada com cana de açúcar. Fonte: CANASAT/INPE.

Assim, a expansão da cana de açúcar está diretamente relacionada às variáveis antrópicas (preço da terra, PIB, IDH e malha viária) do modelo matemático (1). Isto significa que a solução ótima encontrada (Figura 9) procurou minimizar os conflitos existentes entre a conservação e a expansão da cana de açúcar na região.

\section{CONSIDERAÇÕES FINAIS}

Este trabalho procurou apresentar nova proposta para identificação de áreas prioritárias para conservação/restauração da biodiversidade na região que envolve os municípios de Goiânia e Inhumas e as bacias do rio Meia Ponte e a do rio João Leite, considerando a influência das áreas de cana de açúcar. Conforme demonstram os resultados, as áreas prioritárias para conservação da biodiversidade estão concentradas na bacia do rio João Leite e as áreas para restauração, na bacia do rio Meia Ponte, onde se constatou a presença de muitas áreas de cana de açúcar.

Os resultados apresentados, neste trabalho, sugerem ainda a necessidade de se desenvolver novas pesquisas para uma análise mais detalhada dos impactos econômicos, ambientais e sociais provocados pela intensificação/expansão da cana de açúcar sobre a área de estudo, pois, mesmo que o aumento da produção sucroalcooleira traga impactos positivos sobre o desenvolvimento econômico, devem-se considerar os impactos negativos tanto no âmbito ambiental, quanto no social, que incluem a prática disseminada de queimadas para a colheita da cana de açúcar e demanda por 
novas áreas, que podem avançar sobre outras culturas ou áreas de pastagens, ou mesmo sobre áreas de vegetação remanescentes. Esses impactos provavelmente refletirão sobre a estrutura agrária e social da região como um todo.

\section{AGRADECIMENTOS}

Este trabalho contou com o Programa de Apoio à Produtividade em Pesquisa (PROAPP/IFG).

\section{REFERÊNCIA BIBLIOGRÁFICA}

AGNARSSON, G.; GREENLAW, R. Graph Theory: Modeling, Applications, and Algorithms. New Jersey: Person Prentice Hall, 2007. 464p.

ARPONEN, A.; HEIKKINEN, R. K.; THOMAS, C. D.; MOILANEM, A. The Value of Biodiversity in Reserve Selection: Representation, Species Weighting, and Benefit Functions. Conservation Biology. n. 19, 2005, p. 2009-2014.

BANG-JENSEN, J.; GUTIN, G. Digraphs: Theory, Algorithms and Applications. London: Springer - Verlag, 2001.754p.

BONNET, B. R. P.; FERREIRA JR., L. G.; LOBO, F. C. Sistema de Reserva Legal Extra-Propriedade no Bioma Cerrado: uma análise preliminar no Contexto da bacia hidrográfica. Revista Brasileira de Cartografia, v. 58/02, 2006, p. 129-137.

CABEZA, M.; MOILANEN, A. Design of reserve network and the persistence of biodiversity. Trend in Ecology and Evolution n. 16, 2001, p. 242-248.

CABEZA, M. Habitat loss and connectivity of reserve networks in probability approaches to reserve to reserve design. Ecology Letters n. 6, 2003, p. 665-672.

COUTO, M. S. D. S., FERREIRA, L. G., HALL, B. R., SILVA, G. J. P.. GARCIA, F. N. Identificação de áreas prioritárias para conservação da biodiversidade e paisagens no estado de Goiás: métodos e cenários no contexto da bacia hidrográfica. Revista Brasileira de Cartografia v. 62/02, 2010, p. 125-135.

IBGE. Instituto Brasileiro de Geografia e Estatística. Censo demográfico, 2000. Disponível em: <http:// www.ibge.br>. Acesso em: 15/04/2007.

JHA, C. S.; GOPARAJU, L.; TRIPATHI, A.; GUARAI, B.; RAGHUBANSHI, A. S.; SINGH, J. S. Forest fragmentation and its impact on species diversity: an analysis using remote sensing and GIS. Biodiversity and Conservation v. 14, 2005, p. 681-1698.

MARGULES, C.R.; PRESSEY, R. L. Systematic conservation planning. Nature, n. 405, 2000, p. 243-253. MARGULES, C.R.; PRESSEY, R. L., WILLIAMS, P. H. Representing biodiversity: data and procedures for identifying priority areas for conservation. J. Bioscience, n. 27(Suppl. 2), 2002, p. 309-326.

MIZIARA, F.; FERREIRA, N. C. Expansão da fronteira agrícola e evolução da ocupação e uso do espaço no estado de Goiás: subsídios à política ambiental. In: Ferreira, L. G. (Org.). A encruzilhada socioambiental: biodiversidade, economia e sustentabilidade no cerrado (p. 107-125). Goiânia, Editora UFG, 2008. 223p.

MYERS, N.; MITTERMEIER, R. A.; MITTERMEIER, C. G.; FONSECA, G. A. B.; KENT, J. Biodiversity hotspots for conservation priorities. Nature, n. 403, 2000, p. 853-858.

RIBEIRO, Noeli Vicente; FERREIRA JÚNIOR, Laerte Guimarães; FERREIRA, Nilson Clementino. Expansão do Setor Sucroalcooleiro no Cerrado Goiano: Cenários Possíveis e Desejados. In: IX SIMPÓSIO NACIONAL DO CERRADO E II SIMPÓSIO INTERNACIONAL DE SAVANAS TROPICAIS. Anais. Brasília: Embrapa, 2008. 1 Disponível em: http://<simposio.cpac.embrapa.br/simposio/trabalhos_pdf/00489_trab1_ ap.pdf > . Acesso em: 04/01/2011.

SANTOS, R. F. Planejamento ambiental: teoria e prática. São Paulo: Oficina de Textos, 2004. 184p.

SILVA, E. B.; FERREIRA, L. G.; COUTO, M. S. D.; ROCHA, G. F. Taxas de Desmatamento do Cerrado Goiano e do Distrito Federal nos Períodos de 2003 a 2004 e de 2004 a 2005. IX Simpósio Nacional do Cer- 
rado e II Simpósio Internacional de Savanas Tropicais. Anais. Embrapa. Brasília - DF, 2008. Disponível em: <http://simposio.cpac.embrapa.br/simposio_pc210/trabalhos_pdf/00335_trab1_ap.pdf $>$. Acesso em: 04/01/2011.

SANO, E. E.; ROSA, R.; BRITO J. L.; FERREIRA, L. G. Mapeamento semidetalhado (escala de 1:250.000) da cobertura vegetal antrópica do bioma Cerrado. Pesquisa Agropecuária Brasileira, n. 43 (1), 2008, p. 153-156.

Trabalho enviado em outubro de 2011

Trabalho aceito em novembro de 2011 